\title{
Patterns and predictors of statin prescription in patients with type 2 diabetes
}

\author{
Heiner K Berthold ${ }^{*}$, , Ioanna Gouni-Berthold ${ }^{\dagger 2}$, Michael Böhm³, \\ Wilhelm Krone ${ }^{2}$ and Kurt P Bestehorn ${ }^{4}$
}

\begin{abstract}
Address: ${ }^{1}$ Charité University Medicine Berlin, Virchow Clinic Campus, Lipid Clinic at the Interdisciplinary Metabolism Center, Berlin, Germany, ${ }^{2}$ University of Cologne, Department of Internal Medicine II, Cologne, Germany, ${ }^{3}$ University of Homburg, Department of Internal Medicine III, Homburg/Saar, Germany and ${ }^{4} \mathrm{MSD}$ Sharp \& Dohme GmbH, Haar, Germany

Email: Heiner K Berthold* - heiner.berthold@charite.de; Ioanna Gouni-Berthold - ioanna.berthold@uni-koeln.de; Michael Böhm - michael.boehm@uniklinikum-saarland.de; Wilhelm Krone - wilhelm.krone@uk-koeln.de;

Kurt P Bestehorn - kurt_bestehorn@msd.de

* Corresponding author †Equal contributors
\end{abstract}

\section{Published: 13 May 2009}

Cardiovascular Diabetology 2009, 8:25 doi:10.1 186/1475-2840-8-25

This article is available from: http://www.cardiab.com/content/8/I/25

(C) 2009 Berthold et al; licensee BioMed Central Ltd.

This is an Open Access article distributed under the terms of the Creative Commons Attribution License (http://creativecommons.org/licenses/by/2.0), which permits unrestricted use, distribution, and reproduction in any medium, provided the original work is properly cited.
Received: 15 March 2009

Accepted: 13 May 2009

\begin{abstract}
Background: The benefit of statins for prevention of cardiovascular events in type 2 diabetes is established, but a gap exists between guideline recommendations and clinical practice. The aim of the study was to identify patient-related factors predicting statin prescription.

Methods: We assessed the quality of care in 5I,640 patients with type 2 diabetes in a German diabetes registry. Patients were stratified according to primary and secondary prevention. Five-year risk for cardiovascular events was calculated in primary prevention patients. A multivariate adjusted logistic regression model was constructed to determine which parameters influenced statin prescription.
\end{abstract}

Results: $34 \%$ had established atherosclerotic disease and $25.5 \%$ received a statin. Prescription was significantly higher in the secondary compared to the primary prevention group $(38.1 \%[95 \% \mathrm{Cl}$ $37.4-38.9 \%$ ] vs. $18.5 \%$ [95\% Cl 18.0-19.0\%], respectively). In primary prevention the odds for statin prescription increased with estimated cardiovascular risk (OR I.I7 per 5\% increase in 5-year risk, $95 \% \mathrm{Cl} \mathrm{I.II-I.22).} \mathrm{Positive} \mathrm{predictors} \mathrm{for} \mathrm{statin} \mathrm{prescription} \mathrm{were} \mathrm{secondary} \mathrm{prevention,}$ hypertension, former smoking, baseline LDL-cholesterol, and microalbuminuria. The odds of receiving a statin had an inverted $U$-shaped relation with age (nadir, 66 years), age at first diagnosis of diabetes (nadir, 56 years), and body mass index (nadir, $32 \mathrm{~kg} / \mathrm{m}^{2}$ ). The model predicted prescription in $70 \%$ of the patients correctly.

Conclusion: The majority of patients with type 2 diabetes are not receiving statins. The predominant factors determining statin prescription are the patient's prevention status and, in primary prevention, estimated cardiovascular risk. The results suggest that although physicians are aware of the general concept of cardiovascular risk, they fail to consistently implement guidelines. 


\section{Background}

Patients with diabetes have a substantially increased risk of atherosclerotic vascular disease [1]. A recent meta-analysis examined whether statins (HMG-CoA reductase inhibitors) are as beneficial in preventing cardiovascular events in patients with diabetes as they are in those without, and found that in patients with diabetes there was a $9 \%$ proportional reduction in all-cause mortality per $\mathrm{mmol} / \mathrm{l}(\sim 40 \mathrm{mg} / \mathrm{dl})$ reduction on LDL cholesterol, a reduction similar to the $13 \%$ reduction seen in patients without the disease [2]. There were significant reductions in the numbers of fatal and non-fatal myocardial infarctions, coronary revascularisations, and strokes. Moreover, the relative risk reduction was independent of previous history of vascular disease and of baseline subject characteristics.

Current type 2 diabetes guidelines issued by European and American scientific societies recommend lipid-lowering treatment with statins in order to reach the LDL-C target levels of $<100 \mathrm{mg} / \mathrm{dl}$ or of $<70 \mathrm{mg} / \mathrm{dl}$ in individuals with coexisting cardiovascular disease (CVD) [3-5]. However, studies suggest that large discrepancies exist between treatment targets and clinical reality. We have recently shown that the proportion of patients with type 2 diabetes in Germany receiving a statin is low, namely only $25 \%$ [6]. Moreover, only about $6 \%$ of these patients reach all three lipoprotein targets (LDL-C $<100 \mathrm{mg} / \mathrm{dl}$, triglycerides $<150 \mathrm{mg} / \mathrm{dl}$ and HDL $>40$ or $50 \mathrm{mg} / \mathrm{dl}$ in men or women, respectively) [7]. Similarly, reports from other European countries $[8,9]$ and the United States $[10]$ show that not all eligible patients receive cholesterol-lowering therapy.

The reasons behind statin undertreatment are unclear. Statins are available in generic form and they are affordable. However, while in Germany costs for reimbursement are covered by health insurers, physicians' prescribing habits are constrained by a pre-defined overall drug budget. Professional bodies in Germany are reluctant recommending statin therapy for all diabetic patients (e. g. [11]) despite unequivocal evidence of their efficacy from numerous randomized trials and meta-analyses [12-14]. While there is an ongoing debate as to whether diabetes should be considered a coronary heart disease (CHD) equivalent [15], the National Cholesterol Education Programme defined the status of diabetes mellitus already in 2004 as a CHD risk equivalent [16].

The main goal of the present study was to identify patient characteristics predictive of who would receive a statin (or not). For pragmatic reasons, we decided to stratify the patients in bivariate analyses according to primary and secondary prevention before constructing a multivariate logistic regression model including the prevention status. We used the DUTY diabetes registry $[6,17]$ with $>50,000$ patients from all over Germany.

\section{Methods \\ Study design and subjects}

The DUTY registry (Diabetes mellitus needs unrestricted evaluation of patient data to yield treatment progress) is a cross-sectional study in outpatients with type 2 diabetes. The study protocol was approved by the Ethics Committee of the Bavarian Chamber of Physicians. The study design has been published elsewhere [18]. In short, between February 2002 and November 2003 office-based physicians in Germany were approached to participate in the study and to recruit 20 consecutive diabetic patients. Reports of 59,075 patients from 3213 physicians were received. Of these patients, $89.8 \%$ had type 2 diabetes, $5.7 \%$ type 1 , and in $4.5 \%$ the type of diabetes was not identified. For the present evaluation, only patients with type 2 diabetes were considered. Moreover, only data sets where patient gender could be identified were considered. Thus, data of 51,640 patient data sets were analyzed.

Main outcome measure was receiving a statin prescription. We investigated in bivariate analyses factors associated with statin prescription in subjects stratified according to whether they had a history of CHD, stroke, or peripheral arterial occlusive disease (secondary prevention), and in subjects presumed free of atherosclerotic complications (primary prevention).

\section{Definition of parameters}

Diabetes was defined by the treating physician. Hypertension was defined by the presence of antihypertensive drug therapy or by a blood pressure reading of $\geq 140 \mathrm{mmHg}$ systolic or $\geq 90 \mathrm{mmHg}$ diastolic. Lipoproteins, HbA1c, and albumin in urine were determined with routine laboratory methods. Microalbuminuria was defined as albumin excretion in urine $\geq 20 \mathrm{mg} / \mathrm{l}$. Smoking status was documented as self-reported current smoking, former smoking, and never smoking. Glomerular filtration rate was estimated using the Modification of Diet in Renal Disease formula [19].

In the primary prevention group, 5-year risk estimates for the prediction of cardiovascular disease were calculated using the equations developed with the data of the Swedish National Diabetes Registry according to Cederholm et al. [20]. The risk equation contains the following parameters: age at onset of diabetes, duration of diabetes, HbA1c, body mass index (BMI), systolic blood pressure, sex, smoking status, and antihypertensive and lipid-lowering medications.

Lipoprotein concentrations are an important determinant of prescribing a statin. Since in a cross-sectional study there are no baseline 'untreated' levels available, we modelled baseline LDL cholesterol levels in the subjects receiving lipid-lowering drug therapy. The measured LDL levels were corrected assuming a 15\% reduction. This effect size 
was calculated based on the following assumptions: We used the statins prescribed in Germany in 2002 and their daily defined doses [21] and calculated their expected LDL-lowering effect. Statin medication possession ratio (i.e. the number of doses dispensed in relation to the dispensing period) and adherence to treatment (i.e. doses taken in relation to what was prescribed) were assumed to be 50 to $75 \%$ and $50 \%$, respectively, as previously described $[22,23]$.

\section{Statistical methods}

Continuous variables are given as mean values \pm standard deviations. Categorical variables are described as proportions (percentage) and 95\% confidence intervals were calculated from binomial distributions. We stratified all evaluations in our first model according to primary or secondary prevention. Of note, some of the patients had more than one atherosclerotic disease entity (Figure 1).

We used bivariate analyses to examine frequency distributions and variability and we calculated odds ratios and $P$ values for the main outcome measure in a $1^{\text {st }}$ model from simple logistic regression analyses. In a $2^{\text {nd }}$ model, we multiple-adjusted for parameters that were identified in the $1^{\text {st }}$ model. Forward and backward stepwise logistic regression using maximum likelihood-ratio statistics were

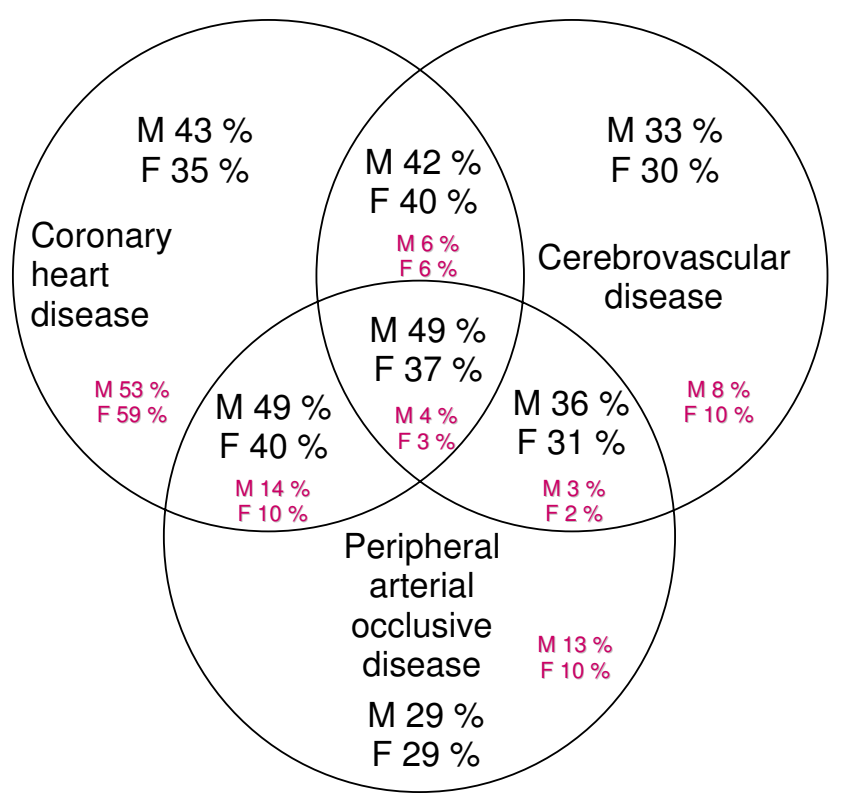

Figure I

Prevalence of the different atherosclerotic disease entities (small figures) and respective statin prescription frequencies (large figures) for men $(M)$ and women (F). Note that some patients had > I atherosclerotic disease manifestation sites, so the numbers may add up to $>100 \%$. used for further support of variable selection. The full model included sex, age, age at diagnosis of diabetes, BMI, smoking status, established concomitant atherosclerotic disease, hypertension, microalbuminuria, estimated glomerular filtration rate, HbA1c, baseline LDL cholesterol, HDL cholesterol, and triglycerides.

Because in 3 variables (age, age at diagnosis and BMI) in bivariate analyses statin prescription was associated with an inverted U-shape of the data (see Figure 2), we added squared terms of these variables. Due to differential prescription patterns seen in primary and secondary prevention (see Table 1), we added the interaction terms 'sex*atherosclerotic disease', 'baseline LDL cholesterol*atherosclerotic disease', and 'smoking status*atherosclerotic disease'. Other interactions were evaluated for inclusion but none was found to improve the model. Missing data on atherosclerotic disease were imputed as 'no known atherosclerotic disease'. Otherwise no missing data imputations were performed. The adequacy of the derived model equation was assessed by standard goodness-of-fit procedures. Sensitivity analysis of the model was performed by repeating the analyses using prescription of all lipid-lowering drugs therapies (e. g., fibrates) rather than the prescription of statins alone. These results were similar and the data are not shown. We used the Statistical Package for the Social Sciences Version 16.1.2 for all calculations (SPSS Inc., Munich, Germany). All statistical tests were performed two-sided and a $P$ value of $<0.05$ was considered significant.

\section{Results}

Patient demographics, comorbidities, and complications Patient demographics and the presence of individual covariates are shown in Table 2. There were $52.9 \%$ of the subjects in primary prevention and $34.0 \%$ in secondary prevention (in $13.1 \%$ the prevention status could not be identified). In secondary prevention, $78.3 \%$ had CHD, $21.2 \%$ cerebrovascular disease, and $25.7 \%$ peripheral artery disease. The prevalence of the different vascular disease entities is shown in Figure 1. More than $83 \%$ in primary and $>94 \%$ in secondary prevention had hypertension. Albuminuria was present in $19.6 \%$ in primary and $39.1 \%$ in secondary prevention.

Overall, in primary prevention $12.6 \%$ of the patients reached LDL cholesterol target levels of $<100 \mathrm{mg} / \mathrm{dl}$ and in secondary prevention $16.3 \%$. The proportion of primary prevention patients in various classes of 5 -year estimated risk can be seen in Table 2 .

\section{Statin treatment: bivariate analyses}

Table 1 shows demographic and clinical characteristics in patients with and without statin prescription. In primary prevention $24 \%$ of the patients were on any type of lipid- 
Table I: Demographic and clinical characteristics in patients with and without statin prescription.*

\begin{tabular}{|c|c|c|}
\hline Characteristic & Statin prescription & No statin prescription \\
\hline Number, (\%) & $13,150(25.5 \%)$ & $38,490(74.5 \%)$ \\
\hline Men (\%) & 27.6 & 72.4 \\
\hline Women (\%) & 23.4 & 76.6 \\
\hline Age (years) & $65.6 \pm 9.5$ & $65.1 \pm 11.3$ \\
\hline Age at diagnosis of diabetes (years) & $58.3 \pm 10.2$ & $58.5 \pm 11.2$ \\
\hline Diabetes duration (years) & $7.3 \pm 6.4$ & $6.6 \pm 6.1$ \\
\hline Body mass index $\left(\mathrm{kg} / \mathrm{m}^{2}\right)$ & $28.9 \pm 4.4$ & $28.9 \pm 4.9$ \\
\hline \multicolumn{3}{|l|}{ Smoking status } \\
\hline Never smoker (\%) & 23.6 & 76.4 \\
\hline Former smoker (\%) & 31.5 & 68.5 \\
\hline Current smoker (\%) & 24.4 & 75.6 \\
\hline Hypertension (\%) & 86.4 & 13.6 \\
\hline Systolic blood pressure $(\mathrm{mmHg})$ & $143 \pm 17$ & $143 \pm 18$ \\
\hline Diastolic blood pressure $(\mathrm{mmHg})$ & $83 \pm 10$ & $83 \pm 10$ \\
\hline Microalbuminuria (\%) & 42.3 & 57.7 \\
\hline Creatinine $(\mathrm{mg} / \mathrm{dl})$ & $1.35 \pm 2.51$ & $1.31 \pm 2.45$ \\
\hline Estimated glomerular filtration rate $(\mathrm{ml} / \mathrm{min})$ & $74 \pm 36$ & $76 \pm 37$ \\
\hline HbAlc (\%) & $7.3 \pm 1.3$ & $7.3 \pm 1.3$ \\
\hline Fasting plasma glucose (mg/dl) & $147 \pm 46$ & $148 \pm 48$ \\
\hline \multicolumn{3}{|l|}{ Lipoprotein concentrations } \\
\hline Total cholesterol (mg/dl) & $221 \pm 53$ & $226 \pm 50$ \\
\hline LDL cholesterol (mg/dl) & $|3| \pm 40$ & $138 \pm 38$ \\
\hline HDL cholesterol (mg/dl) & $48 \pm 13$ & $49 \pm 14$ \\
\hline Triglycerides (mg/dl) & $226 \pm 260$ & $218 \pm 313$ \\
\hline Estimated 5-year cardiovascular risk (primary prevention) & $18.3 \pm 10.6$ & $14.5 \pm 10.1$ \\
\hline \multicolumn{3}{|l|}{ Atherosclerotic complications } \\
\hline Coronary heart disease (\%) & 43.5 & 56.5 \\
\hline Cerebrovascular disease (\%) & 11.0 & 89.0 \\
\hline Peripheral art. occlusive dis. (\%) & 15.5 & 84.5 \\
\hline
\end{tabular}

*Data are means \pm SD or proportions (in \%).

lowering drug therapy and $18.5 \%$ were receiving a statin while in secondary prevention $46 \%$ were receiving any type of lipid-lowering drug therapy and $38 \%$ a statin. Fibrates were prescribed in $5.8 \%$ and $7.9 \%$ of patients, respectively. The respective statin prescription frequencies according to atherosclerotic disease manifestation site are depicted in Figure 1. Statin prescription was higher in men than in women in general and higher in patients with CHD than in patients with cerebrovascular and peripheral arterial disease. Highest prescription frequencies were observed when CHD and peripheral disease were concurrently present.

Table 3 shows bivariate analyses of factors determining statin prescription. Results are expressed in percent of the respective group receiving a statin. Odds ratios for receiving a statin and confidence intervals for binomial distributions can be obtained from the online Additional file 1 .
In unadjusted analyses, women received less frequently statin prescriptions than men. In both, primary and secondary prevention, statin prescription was highest in the $6^{\text {th }}$ and $7^{\text {th }}$ decade of life but declined at higher age. The association with age showed an inverted U-shaped curve (nadir, 66 years; Figure 2A). Similarly, in primary prevention the odds of receiving a statin were lower at younger and higher age at first diagnosis of diabetes (nadir, 56 years), while in secondary prevention the highest prescription rates were seen in patients diagnosed at age $<45$ years (Figure 2B). Diabetes duration had an influence on statin prescription in bivariate analyses (OR per year 1.018, 95\% CI 1.015 to $1.021, P<0.0001)$, but not in multivariate analyses. A body mass index of $>35 \mathrm{~kg} / \mathrm{m}^{2}$ but also BMI values $<25 \mathrm{~kg} / \mathrm{m}^{2}$ decreased the odds of statin prescription when compared with moderate overweight (nadir, BMI $32 \mathrm{~kg} / \mathrm{m}^{2}$ ), both in primary and secondary prevention (Figure 2C). Former smokers had higher odds of 

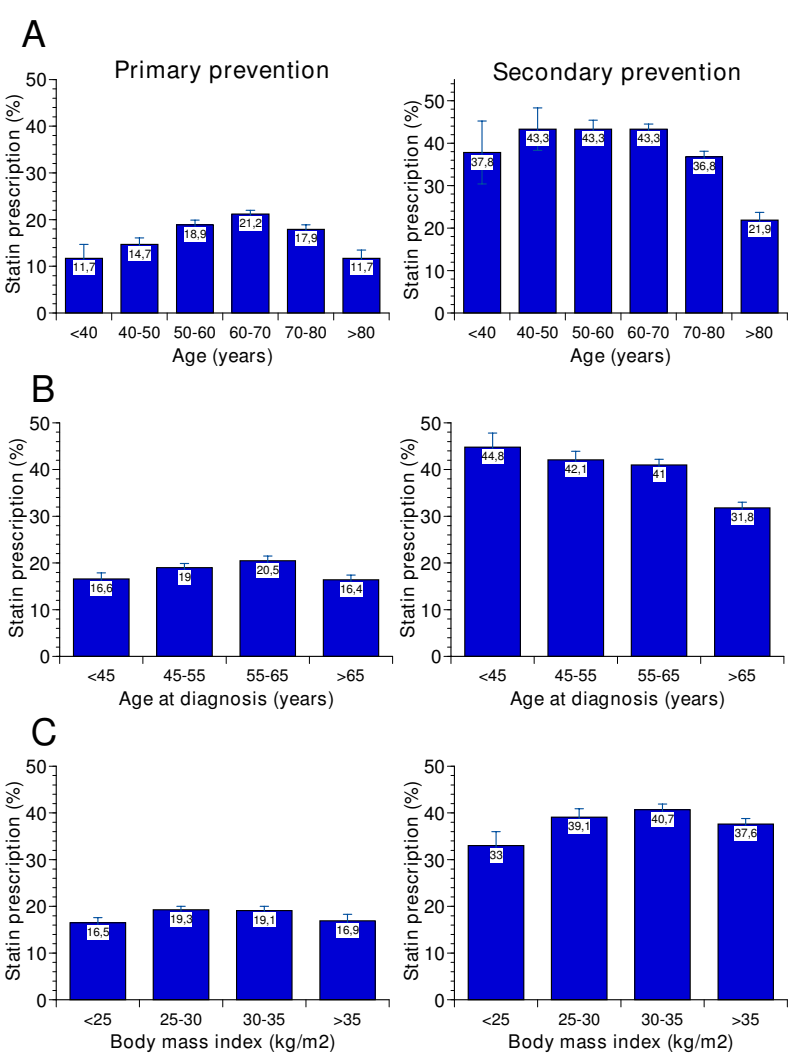

Figure 2

Unadjusted statin prescription frequencies according to age (A), age at diagnosis of diabetes (B), and body mass index (C). Primary prevention data are shown on the left and secondary prevention on the right side. Data are proportions (\%) and $95 \%$ confidence intervals for binomial distributions.

receiving a statin when compared with current smokers and never smokers in secondary prevention. In primary prevention, prescription rates were comparable among never smokers, former smokers and current smokers. The subjects with hypertension had almost doubled odds of receiving a statin (Table 3 and Additional file 1). When albuminuria was present, the odds of receiving a statin increased in comparison to patients with no microalbuminuria (Table 3 and Additional file 1). Glycemic control, as reflected by HbA1c, had no influence and was not included in the final model. Estimated glomerular filtration rate was negatively associated with statin prescription (OR per $\mathrm{ml} / \mathrm{min} 0.998,95 \%$ CI 0.997 to $0.999, P<$ 0.0001 ) in bivariate but not in multivariate analyses. Triglycerides and HDL cholesterol concentrations were not associated with statin prescription.

In primary prevention, there was a continuous increase in prescription frequency from the lowest $(<5 \%)$ to the highest (> 30\%) 5-year estimated risk groups. These data are depicted separately for men and women in Figure 3.

Table 4 shows the results when simulating baseline LDL level conditions. Prescription rates were highest in the groups of LDL cholesterol $\geq 160 \mathrm{mg} / \mathrm{dl}$ in both, primary and secondary prevention, but odds ratios were more pronounced in primary prevention.

\section{Statin treatment: multivariate logistic regression analysis}

The parameters with the strongest association in bivariate analyses, namely presence of atherosclerotic disease and presence of hypertension were included in the model from the beginning. The best fit was achieved using the following covariates: age, age at first diagnosis of diabetes, smoking status, albuminuria, baseline LDL cholesterol, and BMI. Furthermore, the interaction terms 'sex*atherosclerotic disease', 'baseline $\mathrm{LDL}^{*}$ atherosclerotic disease' and 'smoking status*atherosclerotic disease' were all highly significant. All parameters were independently associated with statin prescription, except for sex when the interaction term was used. The respective odds ratios, confidence intervals and $P$-values are shown in Table 5 . Atherosclerotic disease, hypertension, former smoking, high LDL cholesterol, and albuminuria increased the odds for statin prescription, while it was decreased in higher or lower age, higher or lower age at diagnosis of diabetes, and higher or lower BMI. We found some significant interactions: the significant interaction term between atherosclerotic disease and sex indicated that women in secondary but not in primary prevention had lesser odds of receiving a statin. With this interaction term in place, sex by itself was not significant. The significant interaction between atherosclerotic disease and baseline LDL cholesterol indicated that high cholesterol was a stronger predictor of statin prescription in secondary than in primary prevention. The significant interaction between atherosclerotic disease and smoking status indicated that the increased odds of receiving a statin in former smokers were most pronounced in secondary prevention.

Using this model (total $\mathrm{N}=37,110$ patients), correct prediction of receiving a statin was $51 \%$ (sensitivity) and correct prediction of not receiving a statin was $77 \%$ (specificity). The overall proportion of correct prediction of our model was $70 \%$.

\section{Discussion}

Our results demonstrate that the presence of hypertension, high baseline LDL cholesterol, and microalbuminuria as well as a former smoking status, are positive predictors for receiving statin prescriptions. The most important predicting factor is the patient's cardiovascular risk. On the other hand, older or younger age, older or younger age at first diagnosis of diabetes, and higher or 
Table 2: Subject demographics for patients with type 2 diabetes $(n=51,640)$ in primary or secondary prevention*.

\begin{tabular}{|c|c|c|c|}
\hline Characteristic & Primary prevention & Secondary prevention & Prevention status unknown \\
\hline Number, (\%) & $27,322(52.9 \%)$ & $|7,57|(34.0 \%)$ & 6,747 (13.1\%) \\
\hline Male sex (\%) & $45.5 \%$ & $54.2 \%$ & $46.7 \%$ \\
\hline Age (years) & $62.9 \pm 10.9$ & $69.3 \pm 9.5$ & $64.0 \pm 10.8$ \\
\hline Age at diagnosis of diabetes (years) & $57.1 \pm 10.9$ & $61.0 \pm 10.5$ & $57.6 \pm 11.0$ \\
\hline Diabetes duration (years) & $5.8 \pm 5.7$ & $8.3 \pm 6.8$ & $6.3 \pm 5.9$ \\
\hline Body mass index & $29.1 \pm 4.9$ & $28.5 \pm 4.4$ & $29.1 \pm 4.8$ \\
\hline \multicolumn{4}{|l|}{ Smoking status (\%) } \\
\hline Never smoker & $64.8 \%$ & $54.2 \%$ & $52.5 \%$ \\
\hline Former smoker & $17.3 \%$ & $27.7 \%$ & $17.8 \%$ \\
\hline Current smoker & $17.6 \%$ & $15.0 \%$ & $9.0 \%$ \\
\hline Hypertension (\%) & $83.3 \%$ & $94.8 \%$ & $84.8 \%$ \\
\hline Microalbuminuria (>20 mg/l) & $27.8 \%$ & $34.9 \%$ & $31.1 \%$ \\
\hline \multicolumn{4}{|l|}{ HbAlc (\%) } \\
\hline$<6.5 \%$ & $27.3 \%$ & $23.8 \%$ & $26.1 \%$ \\
\hline$\geq 6.5 \%$ and $<7.5 \%$ & $37.0 \%$ & $34.6 \%$ & $35.2 \%$ \\
\hline$\geq 7.5 \%$ and $<8.5 \%$ & $21.1 \%$ & $24.4 \%$ & $22.8 \%$ \\
\hline$\geq 8.5 \%$ & $13.9 \%$ & $16.3 \%$ & $14.5 \%$ \\
\hline \multicolumn{4}{|l|}{ Lipoprotein concentrations (mg/dl) } \\
\hline \multicolumn{4}{|l|}{ Total cholesterol } \\
\hline$<200$ & $27.8 \%$ & $32.4 \%$ & $30.5 \%$ \\
\hline$\geq 200$ and $<240$ & $35.4 \%$ & $32.0 \%$ & $33.2 \%$ \\
\hline$\geq 240$ & $34.7 \%$ & $32.2 \%$ & $35.0 \%$ \\
\hline \multicolumn{4}{|l|}{ LDL cholesterol } \\
\hline$<100$ & $12.6 \%$ & $16.3 \%$ & $14.1 \%$ \\
\hline$\geq 100$ and $<130$ & $25.0 \%$ & $24.2 \%$ & $24.1 \%$ \\
\hline$\geq 130$ and $<160$ & $26.9 \%$ & $23.6 \%$ & $24.6 \%$ \\
\hline$\geq 160$ & $22.6 \%$ & $21.4 \%$ & $21.8 \%$ \\
\hline \multicolumn{4}{|l|}{ HDL cholesterol } \\
\hline$<40(\mathrm{M})$ or $<50(\mathrm{~F})$ & $36.2 \%$ & $39.3 \%$ & $36.0 \%$ \\
\hline$\geq 40(\mathrm{M})$ or $\geq 50(\mathrm{~F})$ & $55.8 \%$ & $53.6 \%$ & $55.2 \%$ \\
\hline \multicolumn{4}{|l|}{ Triglycerides } \\
\hline$<150$ & $30.5 \%$ & $29.0 \%$ & $28.9 \%$ \\
\hline$\geq 150$ and $<400$ & $50.1 \%$ & $51.7 \%$ & $50.2 \%$ \\
\hline$\geq 400$ & $4.5 \%$ & $4.9 \%$ & $3.9 \%$ \\
\hline \multicolumn{4}{|l|}{ On lipid-lowering medication (\%) } \\
\hline Any & $24.0 \%$ & $45.8 \%$ & $31.6 \%$ \\
\hline Statins & $18.5 \%$ & $38.1 \%$ & $25.1 \%$ \\
\hline Fibrates & $5.8 \%$ & $7.9 \%$ & $7.2 \%$ \\
\hline Other & $0.11 \%$ & $0.14 \%$ & $0.10 \%$ \\
\hline \multirow[t]{8}{*}{$\begin{array}{l}\text { Atherosclerotic risk or disease, } \\
\text { respectively }\end{array}$} & $\begin{array}{c}\text { 5-Year atherosclerotic disease risk } \\
(\%)\end{array}$ & $\begin{array}{l}\text { Presence of atherosclerotic disease } \\
(\%)\end{array}$ & unknown \\
\hline & $<5 \%: 11.0 \%$ & Coronary heart disease: $78.3 \%$ & \\
\hline & $\geq 5 \%$ and $<10 \%: 21.9 \%$ & Cerebrovascular disease: $21.2 \%$ & \\
\hline & $\geq 10 \%$ and $<15 \%: 19.2 \%$ & Periph. art. occlussive dis.: $25.7 \%$ & \\
\hline & $\geq 15 \%$ and $<20 \%: 14.0 \%$ & & \\
\hline & $\geq 20 \%$ and $<25 \%: 9.3 \%$ & & \\
\hline & $\geq 25 \%$ and $<30 \%: 5.7 \%$ & & \\
\hline & $\geq 30 \%: 8.1 \%$ & & \\
\hline
\end{tabular}

In 6747 patients (13.1\%) the prevention status was unknown

$*$ Data are means \pm SD or proportions (in \%). 
Table 3: Proportions of statin prescription in bivariate analysis.

\begin{tabular}{|c|c|c|}
\hline Characteristic & Primary prevention & Secondary prevention \\
\hline Number & $\begin{array}{c}\text { Percent statin use } \\
n=27,322 \\
18.5 \%\end{array}$ & $\begin{array}{c}\text { Percent statin use } \\
n=17,57 \mid \\
38.1 \%\end{array}$ \\
\hline \multicolumn{3}{|l|}{ Sex } \\
\hline Male & $18.5 \%$ & $41.3 \%$ \\
\hline Female & $18.5 \%$ & $34.4 \%$ \\
\hline \multicolumn{3}{|l|}{ Age (years) } \\
\hline$<40$ & $11.7 \%$ & $37.8 \%$ \\
\hline$\geq 40$ and $<50$ & $14.7 \%$ & $43.3 \%$ \\
\hline$\geq 50$ and $<60$ & $18.9 \%$ & $43.3 \%$ \\
\hline$\geq 60$ and $<70$ & $21.2 \%$ & $43.3 \%$ \\
\hline$\geq 70$ and $<80$ & $17.9 \%$ & $36.8 \%$ \\
\hline$\geq 80$ & $11.7 \%$ & $21.9 \%$ \\
\hline \multicolumn{3}{|c|}{ Age at diagnosis of diabetes (years) } \\
\hline$<45$ & $16.6 \%$ & $44.8 \%$ \\
\hline$\geq 45$ and $<55$ & $19.0 \%$ & $42.1 \%$ \\
\hline$\geq 55$ and $<65$ & $20.5 \%$ & $41.0 \%$ \\
\hline$\geq 65$ & $16.4 \%$ & $31.8 \%$ \\
\hline \multicolumn{3}{|c|}{ Diabetes duration (years) } \\
\hline$<1$ & $11.4 \%$ & $37.9 \%$ \\
\hline$\geq I$ and $<5$ & $19.3 \%$ & $39.2 \%$ \\
\hline$\geq 5$ and $<10$ & $18.9 \%$ & $38.0 \%$ \\
\hline$\geq 10$ & $20.2 \%$ & $37.1 \%$ \\
\hline \multicolumn{3}{|c|}{ Body mass index $\left(\mathrm{kg} / \mathrm{m}^{2}\right)$} \\
\hline$<25$ & $16.5 \%$ & $33.0 \%$ \\
\hline$\geq 25$ and $<30$ & $19.3 \%$ & $39.1 \%$ \\
\hline$\geq 30$ and $<35$ & $19.1 \%$ & $40.7 \%$ \\
\hline$\geq 35$ & $16.9 \%$ & $37.6 \%$ \\
\hline \multicolumn{3}{|l|}{ Smoking status } \\
\hline Never smoker & $18.1 \%$ & $35.2 \%$ \\
\hline Former smoker & $20.1 \%$ & $44.8 \%$ \\
\hline Current smoker & $18.5 \%$ & $36.0 \%$ \\
\hline \multicolumn{3}{|l|}{ Hypertension } \\
\hline no & $11.7 \%$ & $22.9 \%$ \\
\hline yes & $19.9 \%$ & $39.0 \%$ \\
\hline \multicolumn{3}{|l|}{ HbAlc (\%) } \\
\hline$<6.5$ & $17.8 \%$ & $36.9 \%$ \\
\hline$\geq 6.5$ and $<7.5$ & $19.2 \%$ & $39.8 \%$ \\
\hline$\geq 7.5$ and $<8.5$ & $18.8 \%$ & $36.7 \%$ \\
\hline$\geq 8.5$ & $17.6 \%$ & $38.5 \%$ \\
\hline \multicolumn{3}{|l|}{ Albuminuria } \\
\hline No albuminuria & $17.4 \%$ & $37.4 \%$ \\
\hline $\begin{array}{l}\text { Albuminuria } \\
(\geq 20 \mathrm{mg} / \mathrm{l})\end{array}$ & $19.0 \%$ & $39.1 \%$ \\
\hline \multicolumn{3}{|c|}{ Lipoprotein concentrations (mg/dl) } \\
\hline \multicolumn{3}{|c|}{ Total cholesterol } \\
\hline$<200$ & $19.9 \%$ & $47.2 \%$ \\
\hline$\geq 200$ and $<240$ & $16.2 \%$ & $34.8 \%$ \\
\hline$\geq 240$ & $19.7 \%$ & $32.6 \%$ \\
\hline
\end{tabular}


Table 3: Proportions of statin prescription in bivariate analysis. (Continued)

\begin{tabular}{|c|c|c|}
\hline \multicolumn{3}{|l|}{ LDL cholesterol } \\
\hline$<100$ & $23.8 \%$ & $54.9 \%$ \\
\hline$\geq 100$ and $<130$ & $19.7 \%$ & $42.0 \%$ \\
\hline$\geq 130$ and $<160$ & $16.9 \%$ & $32.0 \%$ \\
\hline$\geq 160$ & $19.0 \%$ & $30.9 \%$ \\
\hline \multicolumn{3}{|l|}{ HDL cholesterol } \\
\hline$<40(\mathrm{M})$ or $<50(\mathrm{~F})$ & $19.9 \%$ & $38.2 \%$ \\
\hline$\geq 40(\mathrm{M})$ or $\geq 50(\mathrm{~F})$ & 19.1 & $39.9 \%$ \\
\hline \multicolumn{3}{|l|}{ Triglycerides } \\
\hline$<150$ & $9.8 \%$ & $37.3 \%$ \\
\hline$\geq 150$ and $<400$ & $20.0 \%$ & $38.9 \%$ \\
\hline$\geq 400$ & $22.9 \%$ & $45.4 \%$ \\
\hline \multicolumn{3}{|c|}{ Estimated 5-year cardiovascular risk (\%) } \\
\hline$<5$ & $6.6 \%$ & \\
\hline$\geq 5$ and $<10$ & $13.9 \%$ & \\
\hline$\geq 10$ and $<15$ & $19.7 \%$ & \\
\hline$\geq 15$ and $<20$ & $23.4 \%$ & \\
\hline$\geq 20$ and $<25$ & $23.9 \%$ & \\
\hline$\geq 25$ and $<30$ & $26.9 \%$ & \\
\hline$\geq 30$ & $26.9 \%$ & \\
\hline \multicolumn{3}{|l|}{ Atherosclerotic complications } \\
\hline Coronary heart disease & & $40.1 \%$ \\
\hline Cerebrovascular disease & & $37.3 \%$ \\
\hline Peripheral arterial occlusive disease & & $38.0 \%$ \\
\hline
\end{tabular}

Subjects were stratified according to primary or secondary prevention and groups were analyzed separately. Confidence intervals and odds ratios for receiving a statin can be obtained from Additional file I.

lower BMI are decreasing the odds of receiving a statin. Since patients with diabetes have a substantially increased risk of atherosclerotic vascular disease, identification of treatment for the prevention of vascular events is a publichealth priority. The NCEP already in 2004 recommended LDL-C goals of $<100 \mathrm{mg} / \mathrm{dl}$ in high-risk patients, including patients with diabetes and an LDL-C of $<70 \mathrm{mg} / \mathrm{dl}$ as an option for very high risk patients [16]. However, statin prescription to every single diabetes patient is a controversially discussed issue. According to the recently published joint guidelines of the European Society of Cardiology (ESC) and the European Association for the Study of Diabetes (EASD) the goals of therapy proposed for diabetic patients in primary prevention are similar to those for non-diabetic patients with symptomatic CVD (total cholesterol $<174 \mathrm{mg} / \mathrm{dl}$, LDL-C $<97 \mathrm{mg} / \mathrm{dl}$ ) [3]. The decision whether statin therapy should be started in patients whose LDL-C is already $<100 \mathrm{mg} / \mathrm{dl}$ is left to individual judgement. In the Collaborative Atorvastatin Diabetes Study (CARDS), statins for primary prevention were investigated in patients with type 2 diabetes without high LDL-C and a significant reduction in major cardiovascular events, including stroke, was found [12]. Further studies confirmed that statins provide a wide range of cardiovascular risk benefit in patients with diabetes, independently of their baseline LDL cholesterol [24]. A meta-analysis in non-diabetic and diabetic patients suggested that diabetic patients, after adjustment for baseline characteristics, benefit even more than non-diabetes patients from lipid-lowering therapy in both primary and secondary prevention [14]. Overall, the evidence suggests that most diabetic patients should receive a statin.

The present study found that only $25 \%$ of patients with diabetes receive statin prescriptions. Prescription frequencies are higher in secondary prevention. Interestingly, in primary prevention, the odds of receiving a statin increased in parallel with the 5-year estimated risk for cardiovascular disease, indicating that prescription decisions are, at least in part, based on risk assessment. Previous studies in non-diabetic populations have shown that patients receiving statins are more likely to have severe cardiovascular comorbidities and to be elderly [25], but a remaining substantive underuse in high-risk patients has also been described [26]. Another interesting finding in our study was that both, the presence of hypertension and albuminuria were associated with increased odds of statin prescription, suggesting that both disease entities are being correctly perceived as predictors of CVD [27]. Surprisingly former smokers had higher odds of receiving a statin than never smokers or current smokers in secondary prevention. It could be postulated that former smokers (i) 

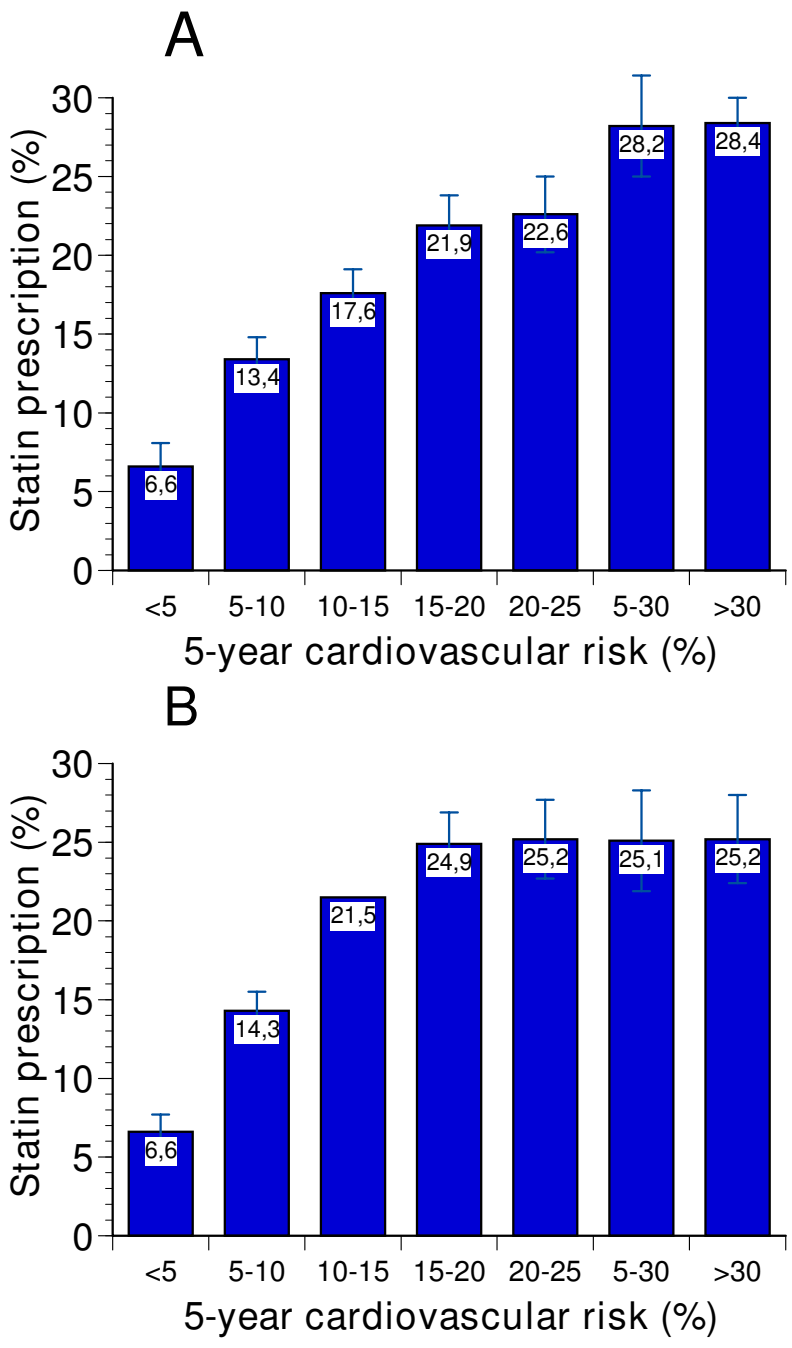

Figure 3

Unadjusted statin prescription frequencies in men (A) and women (B) according to the estimated 5year cardiovascular event risk. Data are proportions (\%) and $95 \%$ confidence intervals for binomial distributions.

are considered to be still at a higher risk than never smokers and (ii) are 'rewarded', consciously or subconsciously, by their physicians for quitting smoking.

We identified three major parameters that were significantly associated with decreased statin prescription: young or old age, younger or older age at first diagnosis of diabetes, and subjects with higher or lower BMI values. Our findings that the elderly receive less treatment are in agreement with those of Teeling at al. [28], who showed a decreased probability of receiving a statin in patients age 65 and older, and to those of Ko et al. [29], who showed that in the elderly prescription of statins diminished progressively as CVD risk increased ("treatment-risk paradox"). In another study it was shown that prescription among patients $>74$ years was $40 \%$ lower than in younger patients [30]. Interestingly, an inverted U-shaped curve association between age and statin prescription was described before [31]. Not only have several studies shown that elderly patients benefit from statin treatment if they have risk factors for vascular disease or established vascular disease $[14,32]$, there is increasing evidence that treatment initiation early in life before the atherosclerotic process has become advanced may be beneficial [33]. The reasons behind fewer prescriptions at higher age may be concerns about treatment complications or shifting priorities for drug treatment from outcome-influencing drugs towards symptomatic treatments in multimorbid patients. Since age is the strongest component of the overall risk score and actual prescription decreases with higher age, the contribution of other risk factors to the odds of receiving statin prescriptions is even greater at higher age.

Our results of increasing statin use with increasing BMI are in accordance to findings of Agalliu et al. [34] and Neutel et al. [26]. However, these studies did not address individuals with BMI $>35 \mathrm{~kg} / \mathrm{m}^{2}$. Our finding of decreased odds of statin prescription above a higher BMI and in normal weight individuals might reflect the physicians' belief that the former will not benefit from such treatment and the latter do not really need it.

We have previously shown that female sex is associated with statin undertreatment in patients with diabetes, especially in secondary prevention [17]. In the present study we confirm these results which are also in agreement to those of other investigators $[31,35,36]$.

For estimating cardiovascular risk in primary prevention we used the newly developed risk equations from Sweden that were specifically designed and prospectively validated in patients with type 2 diabetes [20]. Other risk calculators have been criticized for not providing reliable estimates for such patients [37]. A further advantage of this risk calculator was that in the DUTY registry in more than $89 \%$ of the subjects all necessary parameters were available. Our finding showing an increase in the odds of receiving statin prescriptions in parallel to the increase in the overall 5-year estimated risk is reassuring, since it implies physicians' awareness of the concept of cardiovascular risk or individual risk estimation. The reasons for higher prescription rates in women in comparison to men in the mid-risk range (Figure 3 ) remain unclear.

The possible reasons behind the overall low prescription rates have to be addressed. Drug costs may play an important role in the wide underuse of statins. A study analyzing treatment costs at the time of data sampling of the DUTY registry found that costs for statins were higher than those for all other cardiovascular drugs that were prescribed to patients with type 2 diabetes together and the prescription 
Table 4: Baseline LDL cholesterol levels modelled as 'untreated' (see text for methods)

\begin{tabular}{|c|c|c|c|c|c|c|}
\hline LDL cholesterol (mg/dl) & Primary prevention & & & Secondary prevention & & \\
\hline & Percent statin use & Odds ratio $(95 \% \mathrm{Cl})$ & $P$-value & Percent statin use (\%) & Odds ratio $(95 \% \mathrm{Cl})$ & $P$-value \\
\hline$<100$ & $\begin{array}{c}12.6 \% \\
\text { (II.4 to 13.9) }\end{array}$ & referent & & $\begin{array}{c}39.0 \% \\
(36.9 \text { to } 41.2)\end{array}$ & referent & \\
\hline$\geq 100$ and $<130$ & $\begin{array}{c}14.8 \% \\
\text { (14.0 to I5.7) }\end{array}$ & $\begin{array}{c}1.20 \\
\text { (1.06 to } 1.37)\end{array}$ & 0.005 & $\begin{array}{c}38.2 \% \\
\text { (36.6 to } 39.7)\end{array}$ & $\begin{array}{c}0.97 \\
\text { (0.87 to } 1.08)\end{array}$ & 0.54 \\
\hline$\geq 130$ and $<160$ & $\begin{array}{c}16.2 \% \\
\text { (15.4 to } 17.1)\end{array}$ & $\begin{array}{c}1.34 \\
\text { (1.18 to } 1.52)\end{array}$ & $<0.0001$ & $\begin{array}{c}34.4 \% \\
\text { (32.9 to } 35.8)\end{array}$ & $\begin{array}{c}0.82 \\
(0.74 \text { to } 0.92)\end{array}$ & 0.0004 \\
\hline$\geq 160$ & $\begin{array}{c}28.5 \% \\
\text { (27.5 to } 29.5)\end{array}$ & $\begin{array}{c}2.76 \\
(2.45 \text { to } 3.11)\end{array}$ & $<0.0001$ & $\begin{array}{c}43.3 \% \\
\text { (4l.9 to } 44.7)\end{array}$ & $\begin{array}{c}1.20 \\
(1.08 \text { to } 1.33)\end{array}$ & 0.0009 \\
\hline
\end{tabular}

*Proportions are described as percent and $95 \%$ confidence intervals for binomial distributions. Odds ratios with $95 \%$ confidence intervals were estimated by logistic regression analysis without adjustments.

rates for statins had been increasing 8 -fold in the 10-year period before [23]. However, there is strong evidence to support that the statin-induced reduction of cardiovascular events in diabetic patients, both in primary and secondary prevention, is cost-effective [38]. More importantly, reluctant national recommendations, e. g. of disease management programmes, may play a major role [11].

\section{Limitations}

Our study has several limitations. First, the list of the possible covariates examined is not complete. Statin prescription might depend on other factors not documented in the current registry. For example, the status of the patient's health insurance (private or statutory health insurance) as well as the socio-economic level of the subjects [39] may play a role. Second, physicians reported to the best of their knowledge of statin prescription; hence the data do not account for medication dispensing and adherence rates.
Third, we don't have information about which statin at which dose was used. It is known that many statins are prescribed at doses lower than those shown to be effective in randomized trials [40]. And last, the degree of statininduced lipid-lowering was calculated, not measured. The calculation of a mean lipid-lowering effect of $15 \%$ is only an approximate indicator but simulations with different effect sizes revealed similar results (data not shown).

To our knowledge this is the first study addressing the various predictors of statin prescription in patients with type 2 diabetes. The strength of our findings lies in the heterogeneity and the size of the population investigated and the use of multivariate analyses. By indentifying independent parameters that influence medical decision making in issues of vital importance, such as prescription of statins to patients with diabetes, these results represent a substantial opportunity for improvement in diabetes quality of care. The study contributes to understanding which

Table 5: Results of multivariate logistic regression analysis

\begin{tabular}{|c|c|c|c|}
\hline Covariate & Odds ratio & 95\% Confidence interval & $P$-value \\
\hline Atherosclerotic disease & 7.27 & 5.75 to 9.20 & $<0.0001$ \\
\hline Hypertension & 1.87 & 1.70 to 2.07 & $<0.0001$ \\
\hline Smoking & & & 0.08 \\
\hline Former smokera & 1.16 & 1.03 to 1.31 & 0.014 \\
\hline Current smokera & 1.03 & 0.93 to 1.31 & 0.58 \\
\hline Albuminuria (albumin $\geq 20 \mathrm{mg} / \mathrm{dl}$ ) & 1.06 & 1.003 to 1.16 & 0.037 \\
\hline Baseline LDL cholesterolb & 1.11 & 1.06 to 1.16 & $<0.0001$ \\
\hline Age at first diagnosis of diabetes ${ }^{c}$ & 0.93 & 0.90 to 0.96 & $<0.0001$ \\
\hline$A g e^{d}$ & 0.86 & 0.82 to 0.90 & $<0.0001$ \\
\hline Body mass index & 0.93 & 0.89 to 0.97 & $<0.0001$ \\
\hline
\end{tabular}

aln comparison to never smokers

bOdds ratio for an increase of $10 \mathrm{mg} / \mathrm{dl}$. For details for modelling baseline LDL levels see text

cOdds ratio for an increase or a decrease of 10 years from the nadir, 56 years

dOdds ratio for an increase or a decrease of 10 years from the nadir, 66 years

eOdds ratio for an increase or a decrease of $5 \mathrm{~kg} / \mathrm{m}^{2}$ years from the nadir, $31.6 \mathrm{~kg} / \mathrm{m}^{2}$ 
parameters determine statin prescription but further studies are needed to investigate the reasons for withholding this drug therapy.

\section{Abbreviations}

ADA: American Diabetes Association; BMI: body mass index; CVD: cardiovascular disease; CHD: coronary heart disease; LDL: low density lipoprotein; HDL: high density lipoprotein; DUTY: Diabetes mellitus needs unrestricted evaluation of patient data to yield treatment progress; HbA1c: hemoglobin-A1c; OR: odds ratio; CI: confidence interval; NCEP: National Cholesterol Education Program.

\section{Competing interests}

HKB declares that there is no duality of interest associated with this manuscript. IGB has received honoraria for speaking engagements from Pfizer, Eli Lilly, MSD Sharp \& Dohme and Essex Pharma. MB has received speakers' honoraria from AstraZeneca, Boehringer Ingelheim, Bristol Myers Squibb, MSD Sharp \& Dohme, Essex Pharma, Pfizer, Servier and Sanofi-Aventis. He has been on an advisory panel for AstraZeneca, Boehringer Ingelheim, MSD Sharp \& Dohme, Essex Pharma, Pfizer, Servier und SanofiAventis. WK has received grant/research support from MSD Sharp \& Dohme and speakers' honoraria from AstraZeneca, MSD Sharp \& Dohme, Essex Pharma, Pfizer and Sanofi-Aventis. He has been on an advisory panel for MSD Sharp \& Dohme and Essex Pharma. KPB is an employee of MSD Sharp \& Dohme, Germany.

\section{Authors' contributions}

HKB conceived of the study and its design, carried out the statistical analysis and interpretation of the data and has drafted the manuscript. IGB carried out the analysis and interpretation of the data and has been involved in drafting the manuscript. $\mathrm{MB}$ participated in the design of the registry and has been involved in critically revising the manuscript for important intellectual content. WK participated in the design of the registry and has been involved in critically revising the manuscript for important intellectual content. KPB conceived of the registry and participated in its coordination, acquisition of the data and acquisition of funding. All authors read and approved the final manuscript.

\section{Additional material}

\section{Additional file 1}

Proportions and odds of statin prescription in bivariate analysis of various parameters. Subjects were stratified according to primary of secondary prevention and groups were analyzed separately.

Click here for file

[http://www.biomedcentral.com/content/supplementary/14752840-8-25-S1.doc]

\section{Acknowledgements}

The DUTY registry was supported by an unrestricted research grant from MSD Sharp \& Dohme, Haar, Germany.

\section{References}

I. Haffner SM, Lehto S, Ronnemaa T, Pyorala K, Laakso M: Mortality from coronary heart disease in subjects with type 2 diabetes and in nondiabetic subjects with and without prior myocardial infarction. N Engl J Med 1998, 339:229-234.

2. Kearney PM, Blackwell L, Collins R, Keech A, Simes J, Peto R, et al.: Efficacy of cholesterol-lowering therapy in 18,686 people with diabetes in 14 randomised trials of statins: a meta-analysis. Lancet 2008, 37 I: I 17-I 25.

3. Ryden L, Standl E, Bartnik M, Van den BG, Betteridge J, de Boer MJ, et al.: Guidelines on diabetes, pre-diabetes, and cardiovascular diseases: executive summary. The Task Force on Diabetes and Cardiovascular Diseases of the European Society of Cardiology (ESC) and of the European Association for the Study of Diabetes (EASD). Eur Heart J 2007, 28:88-I 36.

4. American Diabetes Association: Standards of medical care in diabetes - 2008. Diabetes Care 2008, 3 I (SuppI I):SI 2-S54.

5. Grundy SM, Cleeman JI, Merz CN, Brewer HB Jr, Clark LT, Hunninghake DB, et al.: Implications of recent clinical trials for the National Cholesterol Education Program Adult Treatment Panel III guidelines. Circulation 2004, I 1 0:227-239.

6. Berthold HK, Gouni-Berthold I, Bestehorn KP, Bohm M, Krone W: Physician gender is associated with the quality of type 2 diabetes care. J Intern Med 2008, 264:340-350.

7. Berthold H, Gouni-Berthold I, Bestehorn K, Böhm M, Krone W: Cardiovascular risk factors in patients with type 2 diabetes in Germany. Deutsches Ärzteblatt 2007, 104:A 86I-A 867 [http:// www.aerzteblatt.de/v4/archiv/pdf.asp?id=58095].

8. Wood D: Lifestyle and risk factor management and use of drug therapies in coronary patients from 15 countries; principal results from EUROASPIRE II Euro Heart Survey Programme. Eur Heart J 200I, 22:554-572.

9. Tonstad S, Rosvold EO, Furu K, Skurtveit S: Undertreatment and overtreatment with statins: the Oslo Health Study 20002001. J Intern Med 2004, 255:494-502.

10. Abookire SA, Karson AS, Fiskio J, Bates DW: Use and monitoring of "statin" lipid-lowering drugs compared with guidelines. Arch Intern Med 2001, 161:53-58.

II. Kassenärztliche Vereinigung Nordrhein - nordrheinische Krankenkassenverbände: DMP-Vertrag Diabetes mellitus Typ 2 ab 01.07.2008. $2008 \quad$ [http://www.kvno.de/importiert/ dmp diab2 vertrag.pdf]. last accessed November 30, 2008

12. Colhoun HM, Betteridge DJ, Durrington PN, Hitman GA, Neil HA, Livingstone S], et al:: Primary prevention of cardiovascular disease with atorvastatin in type 2 diabetes in the Collaborative Atorvastatin Diabetes Study (CARDS): multicentre randomised placebo-controlled trial. Lancet 2004, 364:685-696.

13. Shepherd J, Barter P, Carmena R, Deedwania P, Fruchart JC, Haffner $S$, et al:: Effect of lowering LDL cholesterol substantially below currently recommended levels in patients with coronary heart disease and diabetes: the Treating to New Targets (TNT) study. Diabetes Care 2006, 29: 1220-1226.

14. Costa J, Borges M, David C, Vaz CA: Efficacy of lipid lowering drug treatment for diabetic and non-diabetic patients: metaanalysis of randomised controlled trials. BMJ 2006, 332: $1115-1124$

15. Bianchi C, Miccoli R, Penno G, Del PS: Primary prevention of cardiovascular disease in people with dysglycemia. Diabetes Care 2008, 31 (Suppl 2):S208-S2I4.

16. Grundy SM, Cleeman JI, Merz CN, Brewer HB Jr, Clark LT, Hunninghake DB, et al.: Implications of recent clinical trials for the National Cholesterol Education Program Adult Treatment Panel III guidelines. Arterioscler Thromb Vasc Biol 2004, 24:el49-el6I.

17. Gouni-Berthold I, Berthold HK, Mantzoros CS, Bohm M, Krone W: Sex disparities in the treatment and control of cardiovascular risk factors in type 2 diabetes. Diabetes Care 2008, 31:1389-1391.

18. Krone W, Böhm M: [Diabetes mellitus needs unrestricted evaluation of patient data to yield treatment progress. The 
DUTY Register]. Bundesgesundheitsblatt Gesundheitsforschung Gesundheitsschutz 2004, 47:540-546.

19. Levey AS, Bosch JP, Lewis JB, Greene T, Rogers N, Roth D: A more accurate method to estimate glomerular filtration rate from serum creatinine: a new prediction equation. Modification of Diet in Renal Disease Study Group. Ann Intern Med 1999, I 30:46 I-470.

20. Cederholm J, Eeg-Olofsson K, Eliasson B, Zethelius B, Nilsson PM, Gudbjornsdottir S: Risk prediction of cardiovascular disease in type 2 diabetes: a risk equation from the Swedish National Diabetes Register. Diabetes Care 2008, 3 I:2038-2043.

21. Schwabe U, Paffrath D, eds: Arzneiverordnungs-Report 2003. Springer-Verlag, Berlin, Heidelberg, New York; 2003.

22. Donnelly LA, Doney AS, Morris AD, Palmer CN, Donnan PT: Longterm adherence to statin treatment in diabetes. Diabet Med 2008, 25:850-855

23. Rathmann W, Haastert B, Icks A, Giani G: Trends in outpatient prescription drug costs in diabetic patients in Germany, 1994-2004. Diabetes Care 2007, 30:848-853.

24. Collins R, Heart Protection Study Collaborative Group: MRC/BHF Heart Protection Study of cholesterol lowering with simvastatin in 20,536 high-risk individuals: a randomised placebocontrolled trial. Lancet 2002, 360:7-22.

25. Yang CC, Jick SS, Testa MA: Who receives lipid-lowering drugs: the effects of comorbidities and patient characteristics on treatment initiation. Br J Clin Pharmacol 2003, 55:288-298.

26. Neutel $\mathrm{Cl}$, Morrison H, Campbell NR, de GM: Statin use in Canadians: trends, determinants and persistence. Can J Public Health 2007, 98:4I2-4I6.

27. Weir MR: Microalbuminuria and cardiovascular disease. Clin J Am Soc Nephrol 2007, 2:58I-590.

28. Teeling M, Bennett $K$, Feely J: The influence of guidelines on the use of statins: analysis of prescribing trends 1998-2002. $\mathrm{Br} J$ Clin Pharmacol 2005, 59:227-232.

29. Ko DT, Mamdani M, Alter DA: Lipid-lowering therapy with statins in high-risk elderly patients: the treatment-risk paradox. JAMA 2004, 29 I: | 864- |870.

30. Gnavi R, Migliardi A, Demaria M, Petrelli A, Caprioglio A, Costa G: Statins prescribing for the secondary prevention of ischaemic heart disease in Torino, Italy. A case of ageism and social inequalities. Eur J Public Health 2007, 1 7:492-496.

31. Lee HY, Cooke CE, Robertson TA: Use of secondary prevention drug therapy in patients with acute coronary syndrome after hospital discharge. J Manag Care Pharm 2008, 14:27|-280.

32. Shepherd J, Blauw G], Murphy MB, Bollen EL, Buckley BM, Cobbe SM, et al.: Pravastatin in elderly individuals at risk of vascular disease (PROSPER): a randomised controlled trial. Lancet 2002, 360: $1623-1630$.

33. Brown MS, Goldstein JL: Biomedicine. Lowering LDL - not only how low, but how long? Science 2006, 3 I I: I72 I- 1723.

34. Agalliu I, Salinas CA, Hansten PD, Ostrander EA, Stanford JL: Statin use and risk of prostate cancer: results from a populationbased epidemiologic study. Am J Epidemiol 2008, 168:250-260.

35. Wexler DJ, Grant RW, Meigs JB, Nathan DM, Cagliero E: Sex disparities in treatment of cardiac risk factors in patients with type 2 diabetes. Diabetes Care 2005, 28:5।4-520.

36. Ferrara A, Mangione CM, Kim C, Marrero DG, Curb D, Stevens M, et al.: Sex disparities in control and treatment of modifiable cardiovascular disease risk factors among patients with diabetes: Translating Research Into Action for Diabetes (TRIAD) Study. Diabetes Care 2008, 3 I:69-74.

37. Coleman RL, Stevens RJ, Retnakaran R, Holman RR: Framingham, SCORE, and DECODE risk equations do not provide reliable cardiovascular risk estimates in type 2 diabetes. Diabetes Care 2007, 30: 1292-1293.

38. Mihaylova B, Briggs A, Armitage J, Parish S, Gray A, Collins R: Costeffectiveness of simvastatin in people at different levels of vascular disease risk: economic analysis of a randomised trial in 20,536 individuals. Lancet 2005, 365:1779-1785.

39. Brown AF, Gross AG, Gutierrez PR, Jiang L, Shapiro MF, Mangione CM: Income-related differences in the use of evidence-based therapies in older persons with diabetes mellitus in for-profit managed care. J Am Geriatr Soc 2003, 5 I:665-670.

40. Shani M, Dresner J, Vinker S: Achieving target cholesterol levels in diabetic patients: potency of the statin or potency of the physician? Isr Med Assoc J 2008, 10:354-357.
Publish with Biomed Central and every scientist can read your work free of charge

"BioMed Central will be the most significant development for disseminating the results of biomedical research in our lifetime. "

Sir Paul Nurse, Cancer Research UK

Your research papers will be:

- available free of charge to the entire biomedical community

- peer reviewed and published immediately upon acceptance

- cited in PubMed and archived on PubMed Central

- yours - you keep the copyright

Submit your manuscript here:

http://www.biomedcentral.com/info/publishing_adv.asp
BiolMedcentral 